

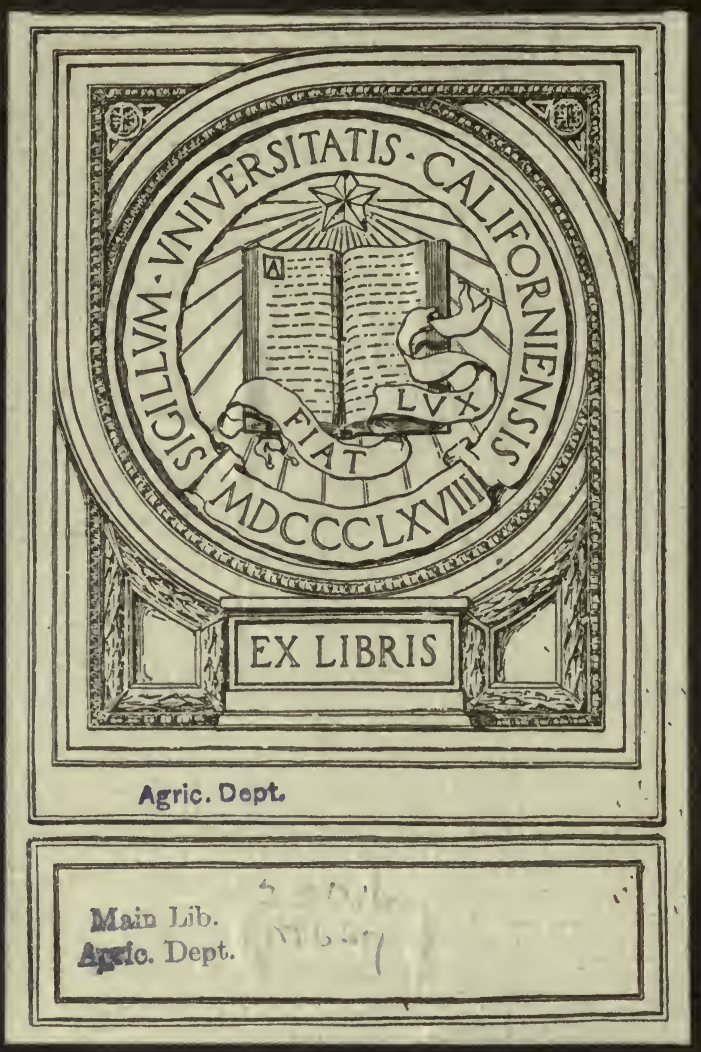




\section{ANNUAL ADDRESS}

DELIVERED BEFORE THE

\section{State Agrieultural SOCIETY \\ OF CALIFORNIA,}

In the Pavilion at Sacramento,

SEPTEMBER 18,1890 ,

BY

WILLIAM H. MILLS.

II

SAN FRANCISCO:

H. S. Crocker \& Co., Stationers, Printers and Lithographers.

1890 . 


\section{Mr. President, and Gentlemen of the}

State Board of Agriculture:

The invitation to deliver thè annual address before your honorable body, received at the hands of your honored President, plainly indicated the questions you desired should be discussed before you. In addition to the indication of the letter of invitation, your President has taken the very proper precaution of discussing with me personally the matters, to which your attention should be called, and the general theme, to which the modest merit of this effort should be addressed.

The annual exhibitions of the State Agricultural Society are designed to be illustrative of the progress of agriculture, horticulture and the mechanic arts in our State. These exhibitions are in the highest sense an epitome of State progress. The inventions of the mind, the work of the hands and the intelligent direction of nature in the production of the objects of human desire, are presented annually for the instruction and the thoughtful consideration of our people. This is the theater of the pride of industry. Here useful toil is crowned with honor, and by that crowning, labor is dignified and ennobled. For thirty-eight years these exhibitions have been held, each exhibition a leaf in the history of the progress of our State. But thirty-eight years is scarcely a yesterday in the history of states and nations. More than this, it is scarcely a noon to the morning of to-day. But, notwithstanding the brevity of time which has elapsed since the foundations of our State were laid, startling contrasts and gratifying comparisons would be disclosed if only the first annual exhibition of this society could be placed side by side with that of to-day.

You need not be told that the American settlement of California was induced by an ardent and expectant search. for gold, but when measuring the progress California has made in field culture, you do need to be reminded that its first occupants and inhabitants had no faith in its agricultural resources. Men are naturally intolerant as to the differences they encounter between the countries with which they are familiar and those they casually visit. Moreover, men in seeking new homes, seek those where the industries they have pursued in the old are the standards of industry in the new. Of the truth of this, every individual has a witness in his own mind. We are not attracted to the countries whose objects of culture are wholly unfamiliar to us. When an exhibition is 
spread out before a spectator, that portion of it with which he is familiar and the result of that industry in which he is engaged will be most attractive, because it will be under the most intelligent and familiar observation. The people of the Temperate Zone, and skilled in the field culture possible in the latitudes of their nativity, find strangely unfamiliar objects of cultivation unattractive, when the proposition to engage in the cultivation of the unfamiliar object is under consideration. It is for this reason that men migrate upon the latitudes of their nativity. They seek new homes with more favorable environment for personal prosperity; but they do not seek a change of industry, which involves the abandonment of that with which they are familiar for the adoption of that which is new. They feel a confidence in the skill and judgment which observation and experience have ripened in their minds, so long as the question of engaging in industries already familiar is presented, but they naturally lose that confidence when methods of agriculture and horticulture, relating to unfamiliar productions, are a part of the problem involved in the change of residence.

The agricultural and horticultural possibilities of California were a sealed book to the pioneer population of this State. The seasons for seed time and harvest were new and strauge. The art of agriculture, as it was known and practiced by themselves and their fathers, was inapplicable here. This is not to be wondered at. The time of growth and verdure, as known to them, was from the spring month of April to the October of autumn. Then followed a winter of death to vegetation, a period of slumber in which all growth was bound in icy chains and laid to sleep in the cradle of winter. To them, spring with its seed time, summer with its ripening suns and autumn with its golden harvests, meant certain specific months of the calendar. They found these months of the old calendar the winter of suspended animation in California. Instead of the June of verdure and blossoms, they found one of russetbrown hills and sun-parched plains, with all the unmistakable conditions of the aridity of death. But on the other hand, they found a later autumn and a longer winter of verdure. Finally the suggestion came that the old almanac was as inapplicable to the seasons of California as the old art of agriculture had proven. Instead of the winter of former experience, they found spring-time to follow harvest, verdure to come with the rains of heaven, growth and vegetation belonging to the months relegated to the rigid bonds of winter in the homes they had left. Slowly the true meaning of the new environment began to be understood. The new art of agriculture followed the suggestion of new vicissitudes in nature, until to-day the art of horticulture and agriculture, as practiced in California, is not known elsewhere in the world, and it is to the material and moral results of this new adaptation of industry to a new environment that your attention is to be called.

You have plainly indicated to me that you desire the matters herein presented for publication. Therefore, what is said herein will go forth with your endorsement. I earnestly ask that before this endorsement is 
accorded, the matter herein presented shall receive your very candid consideration, and its publication to the world shall receive your unanimous consent. In this way it will become your statement, and with this endorsement of your honorable body, it will be received by those who accord it an examination as authentic. It cannot be your purpose to place it before our own people only, and since it is to go forth to the world, to the more deusely populated portions of our common country, from whose borders we are seeking a reinforcenent of our population, an augnentation of its industrial capacity, and additions to the capital available for the development of our diversified industries, let us place ourselves at once in the mental attitude of directly addressing those who are unfamiliar with the resaurces of our State. Let us, if you please, imagine ourselves before an audience of those who desire to change their place of residence, and leave the older and more finished civilizations of our country, for those wherein the conditions of primitiveness still obtain. With the earnest purpose of awakening in their minds an interest in our State, let us be equally earnest in a determination to present the facts fairly and truthfully, so that if any honor us with a change of residence in our favor, the responsibility of disappointing representation will not rest with us.

At the outset we are impelled by candor to admit that the growth of this commonwealth has not kept pace with the growth of the States lying immediately west of the Mississippi river, nor yet west of the Missouri river. Our first immigration was phenomenal. It is estimated that in the first two years after the discovery of gold in California, the alluring opportunity of acquiring great wealth by a sudden turn of fortune in the way of gold discovery, brought to this State 400,000 people. The stories of the fabulous wealth of our mines attracted a population as if by enchantment. That population came uninfluenced by emigration literature, by maps, pamphlets, by taking descriptions, or by any other method or device of recent times to promote the growth of States. The story of gold discoveries in the way of broad placer fields, open to the world, made a strong appeal to the adventurous spirits of all countries. They came by thousands, and they were impelled to come by the hope of greatly improving their condition; in fact, this hope is one of the allurements which change the seat of population from one country to another. Populations are moved from the older to the newer portions of the world in the hope of finding an environment more favorable to personal prosperity. In our own country populations have left the well-developed regions for the more sparsely-settled territories in the hope of acquiring property at undeveloped values and thus securing the advantage of the inevitable and coming development. Allured by the hope of sudden wealth, distance could not discourage and hardship could not deter the great tide of incoming population. In a modified way there is a lesson in this; where actual prosperity exists population comes by the force of an irresistible invitation; where prosperity is merely promised, immigration cau be induced only by argument and 
persuasion. A genuine prosperity in our State will bring us a reinforcement of industrial population uninvited, except by the cogency of prosperity itself.

The gold-seekers formed the basis of our population; they laid the foundations of our social and political structure; they made the mold in which the elements of our civilization were cast. They were an enterprising people to the very verge of being speculative and adventurous. The influences of primitive conditions are very difficult of eradication. The pioneer population of any country gives direction, color and character to its growth. The primitive conditions, therefore, exert an influence upon the character of populations long after those conditions have pasised away. We are by no means entirely emancipated from the influences of our earliest environment. The speculative spirit is at war with methodical and plodding industry. The diligent industry and methodical habits, to which we are so much indebted for the development of our agricultural and horticultural industries, are attributes of more recent growth; hence it may be truthfully said that our population, but forty years old, has less than twenty years of development, when those enterprises and industries relating to its real and permanent sources of prosperity are considered. When success in the search for gold ceased to be as hazardous as a lottery, and successful mining became dependent upon more thoughtful and intelligent methods, for many years the attention of the world was withdrawn from California. This attention was revived with the stock speculative period, the most injurious period in our history. During the many years of its pernicious prevalence, our best enterprise and a large portion of our capital were employed in the discovery and operation of silver mines. In spite of all these, however, the good work of creating a commonwealth, founded upon the enduring industries invited by the fertility of the soil, had gone on, and since the subsidence of the speculative period, has made year by year gratifying progress. Great commonwealths cannot be founded upon the exceptional and the unusual. The wealth of every State and every nation is found in the industrial capacity of its people, and in the direction of this industrial capacity in producing the natural and legitimate objects of human desire. It is, therefore, fairly within the lines of reasonable representation to say that the foundations of California, which are to endure and are to grow into an empire of wealth and population, were laid less than twenty years ago. The real and enduring industries of our State are less than twenty years of age. In this great respect our annals are misleading. We were admitted a State into the Union forty years ago, but the California of the first twenty years of this period saw its morning of promise, its midday splendor of romantic adventure and its declining afternoon. The new creation of this commonwealth is now in its earliest dawn. Our annals may therefore be justly divided into the California of history and the California of prophecy. Forgetting the past and looking to the future, the first consideration which arrests our attention is our geographical position. 
Since the birth of this State, a great economic force has come into operation. I refer to cheap and rapid communication Economic transportation is the equivalent of physical contiguity. Let us make this plain. Go back in the history of production and transportation a hundred years, and you will find that the area of the profitable production of wheat did not extend beyond twenty-four miles from the market for that cereal. The profitable area of production for hay did not reach beyond ten miles of its market. The area of the profitable production of garden stuff, being a little higher class, had a somewhat greater extent. We may, however, safely say that one hundred years ago, the area of the profitable production of all the products of the soil did not exceed twenty-five miles by land. The distance that food products conld be carried by water was far greater, but at the beginning of the present century, twenty-five miles from navigable water constituted the area of profitable production for nearly all species of field culture. Navigable waterways of the country form channels of cheap communication; hence cities and towns sprung up along the banks of navigable rivers; they were marts of exchange. Beyond them a distance of twenty-five or thirty miles, the limit of profitable production was reached. The grazing interests were somewhat better off. Fatted hogs could be driven from roo to r5o miles. Cattle could be driven profitably 500 miles, and horses were known to be taken over a thousand miles. The advent of railroads came, and here around the city in which you are holding this fair, garden vegetables are raised for markets in Denver, Col., and St. Louis, Missouri-even far beyond these limits. Vegetables are raised in the vicinity of this city for the New York market, 3, I88 miles distant. Thus the radius of profitable production sweeps over a limit of land transportation 3,000 miles long, as against a length of twenty-five or thirty miles before the advent of steam transportation by railroad on land and steam navigation on the ocean. We shipped from California in I880, 2,880,000 pounds of garden vegetables. There has been a gradual and steady increase of the shipments under this head until in r 888 they had risen to $32,000,000$ pounds, or more than ten times the quantity shipped in 1880 . The same ratio of increase for eight years more would give us $300,000,000$ -pounds, and who shall say that the proportionate increase will not be realized?

This doctrine that economic communication may become the equivalent of physical coutiguity is the basis of all we hope for. It is the most far reaching and siguificant factor in the future of Califoruia. Three days ordinary wages in England will pay the cost of transportation on one year's supply of breadstuffs for an individual, from the most inaccessible and distant wheat-producing zones of the world. The cost grows less as you approach the seaboard. Breadstuffs are carried distances which are practically unlimited along the commercial pathways of the 
globe. Fruits, green and canned, are exchanged with every portion of the earth, and rice is practically as cheap in one portion of the world as another. Live stock is carried across continents and seas, and live chickens are transported economically 3,000 miles; and dairy products accompany all other articles of commerce. If ten niles from a market on a watercourse was the radius of the profitable area of production of garden stuffs a century ago, and 3,000 miles is the length of the radius now, the countries at the end of that 3,000-mile line are as near to the markets as the gardens were at ten miles. Wheat produced in California may be consumed in London at a lower rate of cost than breadstuffs produced within thirty miles of that city 100 years ago. When the cost of transportation comes to be applied to the retail cost of any article, it becomes inappreciable; for illustration, a pound of wheat in Liverpool has less than a quarter of a cent added to its value by transportation, even when produced in the most inaccessible wheat fields of the world. The lands devoted to the production of cereals then in these most distant fields are in direct competition with the lands devoted to like production in the markets where cereals are produced.

All the assistance rendered by climate and soil in the production of any article is the bounteous gift of nature to the cultivator of the soil. Under the old system, when transportation was costly, countries were widely separated. Under the new system, which is carrying the products of the garden, the orchard and the field half round the world, with inappreciable value added on account of its cost, every portion of the world is in immediate competition with all other portions in the production of the objects of human desire. The competition of soils and climates is immediately present in every market of the world. In these markets, we see the fertility of soils and the favoring conditions of climate competing with the environment of every other portion of the world, where any industrial pursuits are followed. In every market there are immediately present the effects of the systems of labor, the methods of production, the favoring conditions of soil and climate; they meet face to face; distance no longer divides them. Their economic presence has become the equivalent of physical contiguity. Now suppose that in a single township in some of the valleys of California, you have the rigorous climate of Minnesota. Suppose that within that township, the thermometer descends to ten degrees below zero in November, and with the exception of occasional thaws never rises above that indication until March. Suppose that destructive blizzards, accompanied by sleet and snow, rule and reign for six or seven months of the year, would any fruit grower in California be regarded as sane who would plant an orchard within that wintry belt? Now since communication has become equal to contact, will fruit growirg be pursued in any country subjected to the wintry conditions herein described, as against the production of fruit, where spring comes at the end of harvest? Take as an illustration the cost of producing wheat in California. There are no storms in the harvest period; this is equal to twenty-five per cent advantage in the production of the crop. 
Upon this subject Mr. Shippee of Stockton, an experienced wheat grower, says : "First, we have a climate that is wonderfully well adapted "for the production of wheat. In the second place, our lands are level; " are cultivated by large gang plows, from two to eight in a gang, and " handled by one man; while one man is able to plow more in one day " in this State than in almost every other State in the Union, in like " nuanner is he able to sow and harrow more. In the third place, the " machinery used in harvesting enables the wheat grower to harvest his " entire crop at less than half what it costs in any other State, since no " other State possesses these harvesters. Fourth, we have no rains in " the summer to interfere ; we begin harvesting in June and wind up in " October, and are not compelled to take the grain out of the field until "the harvest season is over. No other portion of the wheat producing "zones can do this."

Joseph Cone, a very large wheat grower of the Sacramento valley, confirms these statements, and declares that wheat can be grown for less in California than in any other country of the world. He illustrates graphically the progress that has been made in economic methods of producing wheat by saying that under the old system, when harvesting was done with a sickle, threshing done with a flail and separating done by the primitive method of a fan, a tenth of an acre was as much as a single harvester could cut, thresh, separate and sack in one day; or, in other words, it would require the labor of ten men to harvest, separate and sack one acre of wheat, but with the machinery now in use the result is seven and one-half acres a day for each man employed in harvesting, or seventy-five times the productive capacity of an individual harvester under former systems.

Hon. H. M. La Rue says: "That wheat may be raised more economi" cally in California than elsewhere is perfectly tenable. Our wheat "lands are generally level, uniform in quality ; our soil is rich and easily " worked. Our system of summer fallowing enables us to do our plow" ing in the spring, and our seeding in the long days in the fall before "the rainy season commences. Owing to our long dry summers, we " have ample time for harvest, without danger from wet weather. Our " climate also enables us to use the most improved machinery, both in " seeding and harvesting. The combined harvester can be used to better " advantage in California than in any other wheat-growing country, and " by its use we have been enabled to reduce the cost of harvesting, "threshing and cleaning sixty per cent of what it costs in other coun" tries."

I present the testimony of these intelligent and experienced gentlemen, practical wheat growers, as conclusive of the assertion that wheat can be grown more cheaply in California than elsewhere. The full significance of this can scarcely be realized. Now if the advautages of soil, climate and general environment are present in every market in the world, California can raise breadstuffs at a price which would be unremunerative to any other portion of the wheat-growing zone. Distance 
being no longer a factor, whenever the test comes under which the fittest survive, wheat growing in California would continue in this State long after its discontinuance elsewhere. At the same market rate, therefore, the wheat producer of California receives a higher reward for his labor. Keeping in mind the position taken at the outset, that we are saying these things to an intending emigrant, to a farmer in Iowa or Illinois, can we not say with truth to him that the labor he puts upon his fields in those States would reward him better if expended upon fields in California? And is this not an inducement which would lead him to decide in our favor when seeking a new home? Let us reverse the illustration. Suppose that in an Eastern State, in a single county of Ohio, Minnesota or New York, there is a climate where storms in the harvest period are unknown, where hailstorms and windstorms do not waste the ripening grain, and where the gang plow and seeder may be run in seeding season and the harvester may be run in harvest time, would other land in that country bear an equal rate to that lying under this favored zone? I repeat again, what cannot be too strongly impressed, that modern methods of transportation produce economies of production, equal to nearness of contact, and that the competition of climates between different portions of the earth is present in every market.

The ultimate operation of this principle will be to produce every article where its production affords the greatest reward to the labor devoted to its production. No fiscal policy or tariff device will very long delay, nor eventually wholly prevent, the universal sway of this principle of production. Each object of human desire will be produced in the country where its production costs the minimum of human effort. This principle is inherent in the human mentality. It is inseparable from human desire, because it is the desire of mankind to get the maximum return from the minimum outlay of effort. Mankind, as a whole, will then sooner or later, adopt this principle of production, appealing to that natural subsidy, which favoring conditions bounteously confer upon those products, grown in the soil and in the climate most promotive of their growth. Apply this principle to the entire round of production in California, and you will perceive that the orchards of California and the vineyards of this State are in immediate competition in the markets of the world with the orchards and vineyards of every other country; that it is possible, therefore, for us to become the orchard for the whole world, in its broad and commercial sense. The modern econonic methods of transportation have placed orchards, physically distant from eacl other, side by side in a commercial sense, and the tendency of this large factor in controlling and directing the industries of every country cannot be thwarted or arrested. This force is the great basis of reciprocity toward which national opinion is so strongly tending. 


\section{REDUCTION OF COST OF TRANSPORTATION.}

To the average Eastern mind, California and its sister Pacific States are on the verge of the continent. Their names are associated with great distance. When they are under consideration as the objective point of a future residence, contemplation is associated with discouraging remoteness. Between California and the fertile area of the Eastern States there lies an uninhabited region. Between the two groups of civilization, that facing the Atlantic and that facing the Pacific Ocean, there are $1,500,000$ square miles of territory, the average fertility of which is less than one-fiftieth the average fertility of the territory lying east of the Missouri river. To the emigrant from an Eastern State to California, the consideration of distance involves the breaking up of home ties, old associations, old acquaintanceship. The distance is too great for the maintenance of old associations. Nor are these things even the most serious source of discouragement. The people of the East regard California as being under special disadvantage with reference to its commercial relation to the rest of the world. To the most casual observation, California labors under a great disability with reference to transportation. It pays the highest price for all supplies imported, and it submits to the greatest discount in consequence of the cost of transportation upon its exports. But, as has already been shown, cost in its commercial sense, is convertible into distance. If it costs the same to ship goods from San Francisco to New York as from the Missouri river to New York, then, commercially, Califoruia is as near the great metropolis of the country as the Missouri river. As specially instructive, I beg leave to present the following terminal rates over a period of nine years from r 880 to 1889 : 


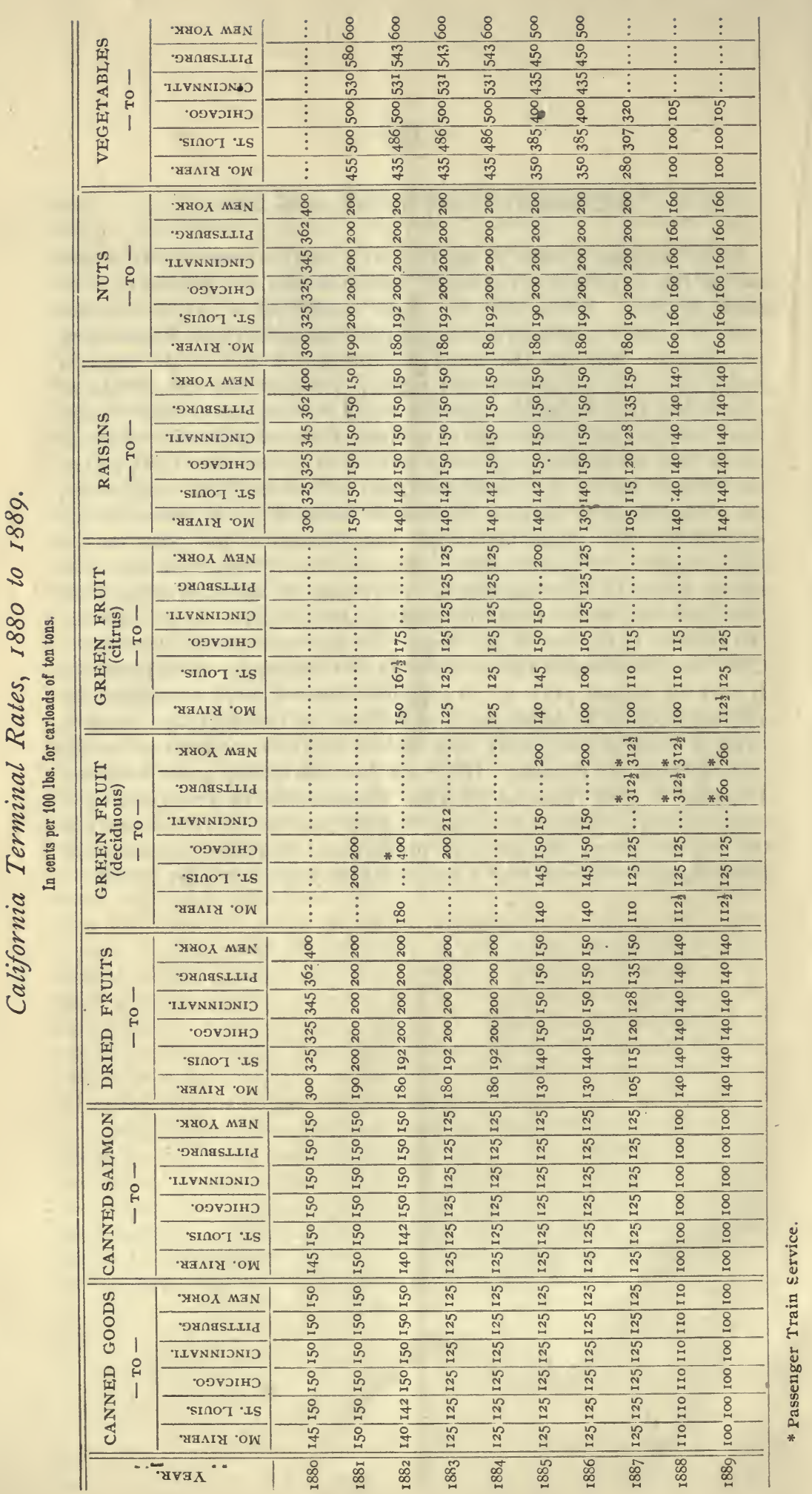


From the foregoing it will be seen that the rate on canned goods per carload in I $\$ 80$ was $\$ 300$ per car to the Missouri river, to St. Louis, to Chicago, to Cincinnati, to Pittsburg and to New York. This rate had descended in 1889 to $\$ 200$ per car to these six principal centers of distribution. In a commercial sense, therefore, the distance to all these places became equal, notwitlıstanding the difference of distance from Sacranento to the Missouri river as against New York is 2,000 miles. Thus a distance of 2,000 miles is absolutely ignored, and New York has exactly the same commercial relation to Sacramento as the Missouri river. It will not be unprofitable here to reannounce the principle that economy of communication is the equivalent of physical contiguity, for in the instance above recited, we see that the cost of reaching New York with the products of this State is exactly the same, or no greater, than the cost of reaching a point two thousand - miles nearer to us.

Glancing at the entire list, we find that canned salmon was carried in I 880 at the rate of $\$ 300$ per car to the six cities named, and that the rate last year was $\$ 200$ per car; that the rates on dried fruits in 1880 were $\$ 600$ a car to the Missouri river, $\$ 650$ to St. Louis, $\$ 724$ to Pittsburg, and $\$ 800$ to New York, and that they descended in the year 1889 to $\$ 280$ a car to the cities named. Green fruit (deciduous) was shown like favors. The rate on raisins to the six cities named in I880 was $\$ 600$ a car to the Missouri river and $\$ 800$ to New York. In I899, the rates were equalized to $\$ 280$ to each of the cities named. On vegetables, the rate in I88I was \$9ro a car to the Missouri river, and in I889, to the same point, the rate was $\$ 200$ a car. Taking this last instance of vegetables, and the rate in I88I was about five times the rate charged to-day. Thus the vegetables produced in California are carried to-day at about twenty per cent of what was claimed to be the proper rate eight years ago. If the above comparisons had been instituted between the rates of 1870 and 1890 , the decrease would have been much more significant and startling. But the other side of the fact is equally significant. The rates on articles of import have experienced a corresponding decrease.

The chief significance of all this is in the question of the elimination of distance. When the rate to Chicago in I88I on vegetables was $\$ 5$ per Ioo pounds, or $\$ 1,000$ per car, the commercial distance to Chicago was five times greater than in 1889 , when the rate was $\$$ r per Ioo pounds, or $\$ 200$ per car. The actual distance to Chicago in miles is 2,275 miles. The rate in I88I was $\$ 5$ per 100 pounds, or $\$ 1,000$ per car. This rate having descended in 1889 to $\$ 200$ per car, or one-fifth, removed Chicago to within 455 miles of the gardens of California, thus eliminating and ignoring $\mathrm{I}, 820$ miles of transportation, on the basis of the rate in $\mathrm{I} 88 \mathrm{I}$ :

These facts disclose a tendency in transportation to base all rates upon the relation of markets to each other rather than the distance in miles between then. It is within the bounc's of reasonable probability that within a few years, this tendency will have so far asserted itself that the only question will be the relation between the points of production and points of consumption, with scarcely a reference to the distance in miles which 
separate them. Take, for example, dried fruit, and referring to the table, see how this tendency has already produced results. In I880, the rate on dried fruit to the Missouri river was $\$ 3$ per 100 pounds, or $\$ 600$ per car. The rate to New York was $\$ 4$ per roo pounds, or $\$ S 00$ per carload. In 1899 the rates had descended to an equal rate of $\$ \mathrm{r} .40$ per roo pounds, or $\$ 280$ per car. This readjustment and equalization of freight rates, disregarding the difference of distance between the points named, was controlled and adjusted by the standard of the commercial relations between the producer and the consumer, since difference of distance is practically lost sight of. The significance of this tendency to the industries of California, both as to its downward character and to its disregard of distance, cannot be overestimated. It means that in the near future the products of California will stand in the markets of the world on terms of perfect equality as to the cost of reaching markets, with the products of all other countries.

\section{THE INDUSTRIES OF CALIFORNIA AND THEIR FUTURE.}

Our Eastern friends, even many of our own citizens, are constantly predicting the speedy, approach of a condition of overproduction. This apprehension both at home and abroad has exerted a strong influence in retarding our growth and development. It is time the matter was placed at rest, and the question which confronts us at the outset of its discussion is, what are the facts and what are the most reasonable inferences to be drawn from these facts? Enterprising men everywhere look to the future with the most serene confidence, and when that confidence is challenged we find it to rest in the great common-sense proposition that no country has ever yet been ruined by its excessive fertility or the expanded possibilities of its climate.

The vast diversity of agriculture and horticulture in California places our industries in competition with the industries of nearly every climate and zone of the habitable earth. In this diversity our safety resides. As a wheat-producing country alone we would share the vicissitudes of the wheat zones of the earth. Failure of crops or of prices would inflict upon us constantly recurring years of loss, but our climate admits of the production of every object of cultivation grown on the entire face of Europe. The list embraces many articles which have but a very limited area of production on the earth, and, fortunately for us, these articles are in the list of those which cannot be produced by the countries sustaining the largest populations of the world.

Let us take first the question of citrus fruit. That industry in California is still in its infancy, notwithstanding it lias loug sincé passed its experimental stage. Citrus fruits are now produced in commercial quantities. Thirty years ago there was imported into the United States 300,ooo boxes of citrus fruit. Last year Florida contributed to supply the demand 600,000 boxes and California contributed 780,000 boxes. Thus 
the country into which thirty years ago were imported 300,000 boxes of citrus fruit produced within its own borders last year 1,380,000 boxes. What were the facts as to importation in the same year? From the report of the Senate Finance Committee, compiled for the use of the Senate of the United States, in the discussion of the McKinley Bill, and gathered from the most authentic sources, to wit, the custom-house returns of the United States, it is shown and declared that in 1889 there was imported into the United States of citrus fruits $3,354,963$ boxes and 113,927 barrels. Thus, notwithstanding the contribution of Florida and California to the volume of supply, the importation of citrus fruits into the United States was more than eleven times that noted prior to the beginning of home production. In the face of these facts, is it competent for any man to predict overproduction of oranges and lemons in California and Florida? The entire demand of the United States thirty years ago was imported. When this country becomes a producer to the extent of $x, 380,000$ boxes, the importation in the same time has arisen to nearly $4,000,000$ boxes, thus constantly widening the margin in favor of the home producer and forever silencing all prophecies of overproduction.

I take the liberty of introducing here the testimony of an intelligent representative of Southern California. Major E. W. Jones, President of the Los Angeles Chamber of Commerce, under date of August 2Ist, says :

"The citrus culture of Southern California has been successfully " prosecuted for so many years as to establish the fact beyoud con" troversy that our climate and soils are adapted to it. Over roo years " ago the Mission Fathers planted orange trees at San Gabriel, ten " miles east of Los Angeles, and some of these trees are still living, in "spite of half a century of neglect. In the past thirty-five years only " has citrus culture in California been engaged in as a commercial ven" ture. Sixteen years ago orchardists in the San Gabriel'valley and Los "Angeles city found markets for their fruits and realized $\$ 1,200$ an acre "for oranges. The fruit on about thirty acres was sold at that " price. That was the first opportunity for reaching the outside markets. " Since then the planting of citrus orchards all through Southern Cali" fornia has been going on until now in Los Angeles county alone there " are eighteen thousand acres. The shipments of citrus fruit, including "lemons and limes, last year were 827,000 boxes from Southern Califor" nia. Leading shippers of our section estimate the crop of next year " to be 4,000 carloads. Markets for the fruits and facilities for reaching " them increase in greater proportion than the production, while the cost "of transportation is continually cheapeniug."

The second instance to be cited here will relate to raisins. In 1874 we shipped East 200 pounds of raisins. In 1888 we shipped 18,000,000 pounds, and the extent to which we failed to supply the home market is fully illustrated by the report of the Finance Committee, already quoted, wherein it is declared that there was actually imported into the United 
States in the year $188934,393,500$ pounds of raisins. When, therefore, California has trebled its present product of raisins, it will barely equal the importation. To state this in a different form: The volume of importation is twice that of the product of California. Since California contributes to the demand $18,000,000$ pounds at the present rate of production, and since there were, in round numbers, 35,000,000 pounds imported, there is on the present basis of consumption a perfectly safe and certain demand in the United States for three times the vineyard capacity now existing. When, therefore, we are told by the Eastern and home objector that the iudustry of raisin-growing will be overdone, let us remember that the demand will increase, and that the present demand in the United States is three times our present capacity for production. There is therefore room for three vineyards for every one now cultivated in California.

How does the case stand as to grapes and prunes? These will be considered together, simply because they were treated together in the report of the Finance Committee to the Senate. The importation of these two articles in 1889 was $47,493,210$ pounds. Are we in danger of overproducing grapes and prunes while the fiscal reports of the nation exhibit this vast volume of importation?

Take even the case of lumber. Those but partially informed will naturally conclude that the forests of our country supply all our home demands, and yet in 1889 the report already quoted states that there was imported into the United States 537,000 , o0o feet of lumber, the Customhouse valuation of which was $\$ 1,050,000$. Of olive oil there was imported into the United States 454,000 gallons, of sugar 9,128,000 pounds and of wool $132,817,456$ pounds.

Are our industries likely to be overdone while this vast volume of importation of the industries of other countries must be availed of to supply the home demand? But there is another and a better view to be presented of the future of our leading industries. The following tabular statement presents under examination a very hopeful exhibit: 


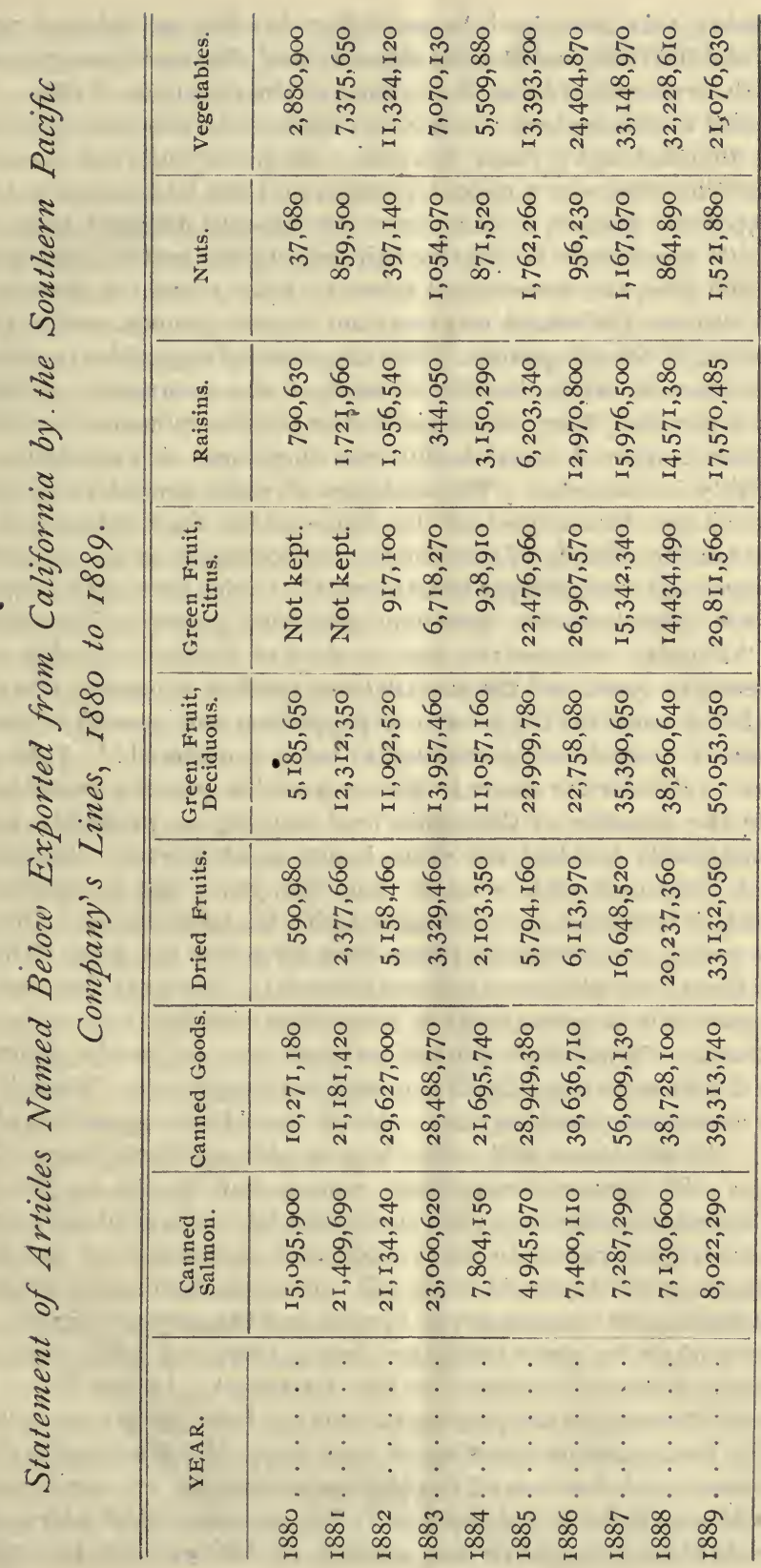


Reviewing this table, let it be noted that in 1880 we shipped 590,000 pounds of dried fruit, and that the shipments of 1889 reach over $33,000,000$ of pounds, or sixty-five times the volume of the shipment of 1880 . Thus we supplied to the markets of the East in $r 889$ sixty-five times the annual volume supplied eight years previous. Of green fruit, the amount of shipments in I880 was $5,180,000$ pounds, and this had arisen in I889 to over $50,000,000$ pounds, or ten times the amount shipped nine years before. Of citrus fruits in 1882 we shipped 917,000 pounds, and in 1889 , seven years later, the amount had arisen to fully $20,000,000$ pounds. In I880 the shipment of raisins was less than 800,000 pounds, and in I889 it had reached $18,000,000$ pounds. The shipment of vegetables in 1880 was $2,880,000$ pounds, while in 1887 it reached the enormous quantity of $33,000,000$ pounds. The commercial forces and the industrial conditions, which have conferred upon us this vast increment of exportation, are still actively in existence. The analogies all point toward a still greater increase. Upon this subject of the future of the fruit industry of California, I take the liberty of introducing the testimony of an experienced fruit grower and fruit shipper in California. Under date of July 25th, $\mathrm{H}$. Weinstock, a well-known merchant and fruit grower, of Sacramento, says : "You say, "suppose the fruit product of California double within " "the next five years, will the market be as good as at present, due allow" 'ance being made for the growth of population and growth of market, " 'no unusual cause favoring the market being considered?' Taking the "past as a guide for the future, my answer to this question would be that "double the quantity of California fruit can be as profitably and as "advantageously handled five years hence as at present. Though our "market compared with what it was five years ago is wonderfully " widened, it is limited as yet compared with the possibilities. There are "many towns, and cities and places that have not yet seen California "green fruits, and who can use quantities of it. The next five years will "see a wouderful progress made in connection with fruit culture in many "directions. We will have quicker railroad time on freight shipments. "We will have more scientifically constructed freight cars. We will have " much lower transportation rates. We will have larger quantities of finer "fruits. We will know still better how to pick and pack them. There "will be still greater competition among fruit buyers in the East, " and this keener competition will force these buyers to send out laterally, "so to speak, for trade into every nook and corner east of the Rocky "Mountaius, until California fruits will become as thoroughly distributed "in the East as are the oranges of Florida and the grapes of Spain."

"Our markets for green fruits are being increased with remarkable " rapidity. Let me illustrate this last statement. In the fall of 1886 , " while in Chicago for the purpose of looking into the serious situation " on the fruit question existing at that time, Mr. Washington Porter, " who was regarded as one of the highest authorities on the marketing " of California fruits in the East, and who, on being asked why so many " carloads of fruit that were then rotting in Chicago for the want of 
" buyers were not shipped East, said in reply, that experience had shown "that the Atlantic markets could not handle carloads of fruit, and that " all that could be successfully marketed east of Chicago, or even in such "great cities as New York and Boston, were daily express lots from Chi" cago. He said that California was already raising too much fruit, and " that we could never hope to successfully market the vast acreage at that " time already planted and that must come into bearing the following "several years. Fortunately for California, time has shown that the " gentleman was a false prophet, that the trouble was not with the mar" ket, but the manner in which the market was handled. A change in "our method of selling California fruits in the East has brought about a "wondrous change in results. Aside from the express lots that were "sent on daily from Chicago, but one carload of green fruit was shipped " east of that point in I886 and was sold at a loss. In I 887 the method " of selling California fruit by auction in the Atlantic cities was first "introduced, and that year Ioo carluads were sold in Boston and New "York at very satisfactory prices. In I 888200 carloads were sold in " Boston and New York at still more satisfactory prices. In I889 400 "carloads were sold in these markets at a higher average of prices than " ever before reached in the sale of California fruits, and this year, I am " told, 800 carloads can be disposed of at equally satisfactory prices."

The facts are then that the importation of the products of California have constantly augmented, that the shipments of our products have increased year by year, and that increase has been attended by a constant decrease of rates. Recurring to Mr. Weinstock's testimony, we find in I 886 one carload of California fruit went to the markets east of Chicago and was sold at a loss. We find that up to this time in the year 1890 , and only four years from the former date, 800 carloads were sold in the markets of Boston and New York at the highest prices ever realized. There is not a single statement of fact which may be quoted in justification of any apprehension that any of our industries are in danger of being overdone. On the contrary, we are contributing to human necessities, producing the legitimate objects of human desire, and we are producing these under conditions so favorable to their production as in themselves to afford a guarantee against successful competition.

While the foregoing relates chiefly to the production of fruit, the conditions influencing other products, and having a direct bearing upon their future, are completely analagous. It certainly cannot be said of our State that its industries are overcrowded, when its products are imported into the United States in a vast volume. It cannot be said that the industries of our State are overcrowded, when it is remembered that during the year 1889 we imported into California for the consumption of our own people $\$ 800,000$ worth of eggs, and from $\$ 15 \dot{0}, 000$ to $\$ 200$, 000 worth of poultry. We are large importers of butter, of lard and of pork. And beyond all this, we are very large producers of raw materials, which sooner or later will be economically and profitably manufactured here. The exportation of raw material to become valuable by added labor and 
skill in other countries, is a process of impoverislment. Keeping in view that we are now addressing our Eastern friends and answering Eastern inquirers, we may say to them in perfect good faith that our manufactures are largely in their infancy, and that the conditions here favor the successful prosecution of manufactures. With respect of manufactures, we are perhaps behind any or all of the Eastern States. Our people are beginning to realize this. We are beginning to understand that when we ship away from our State raw material to be tanned into leather, and the leather to be converted into footwear, we are shipping from us the opportunity of creating wealth, an anount which is readily measured by the difference between the value of the rawhides and the value of the footwear manufactured from the rawhides. Likewise the wool which is raised by our people is shipped in the staple, and we lose the opportunity of adding labor and skill, which would give us the value of the cloth manufactured. At the end of a year, in the ledger account of the industries of a great commonwealth, the' test of its wealth-producing capacity is the amount of value added to raw material by labor, skill and intelligently directed industry. Our protection of breadstuffs is certainly not overdone. We would find it a difficult task to overdo the production of precious metals, the "manufacture of iron, or manufactures of lead and copper. Thus we may truthfully proclaim to the world that California offers an opportunity for field culture, manufactures and mining such as no other State in the Union may claim; that none of the industrial pursuits of our country are even at the meridian of their development; that all without exception await the vitalizing influence of enterprising capital and industry.

\section{THE QUESTION OF LABOR.}

For many years the people of the world were taught to believe that California was not an inviting field for honest industry in the realm of common labor. This was true of its early history. The distance to this State and the cost of getting here, and the rate paid to common labor in this State were all such as to operate as a discouragement to the coming of an intelligent, self-respecting European labor. The competition also of Chinese labor was an additional discouragement. But it is chiefly with the labor market of to-day that we are to deal, and while its adequate treatment would be beyond the reasonable space allotted in a paper of this kind, some of its most salient features will be considered.

It is a regrettable fact that the unions of skilled laborers are opposed to all efforts to induce their craftsmen to come to this State. Their objection, if we are to trust the expressions of their representatives in conventions, is that the coming of additional men produces a condition of things menacing to the maintenance of high wages. The fundamental error of all this is that growth of population in any country is attended by the expansion of its industries and the increase of employment 
rather than its decrease. The coming of additional population to California to engage in any pursuit or undertaking, of any nature whatever, is an unmixed good. The chief obstacle in the Pacific States to the successful prosecution of all enterprise is the sparsity of population. There are economies of production, possible to large populations, which are unknown to thinly settled countries. The best market for the products of every country is the home market. Take the cases already referred to. We ship wool from California and submit to a reduction equal to the cost of freight and commission, and we wear the clothing manufactured from that wool, to which has been added the skill and industry which have enriched another country, with the freight cost and commission added to the manufactured article. The difference between the economy of manufacturing at home, therefore, represents the cost of shipping raw material to the place of manufacture and the cost of shipping the manufactured article or clothing back again, and also represents the loss of the opportunity to create wealth by the amount of the difference between the staple and the fabric. This in our case constitutes a very large margin in favor of manufactures. Our population is estimated at I,250,000. Let us for a moment anticipate the result if that population were doubled, and the population of California stood in the census report at $2,500,000$. Would the natural resources of the country be inadequate to the eniployment of its people? In the first place, we would have an accession of $1,250,000$ home consumers. We would have double our present capital. We would have double the supporting population for every species of industry and enterprise. The local rates of transportation would at once descend, because the same fixed charges would answer for the new as well as for the present demand; and the net result of that augmentation of population, that enterprise and capital, that addition to every element of civilized life, would be an increase in geometrical rather than arithmetical ratio; the products of all employments would be more than doubled, and the opportunity and condition of the labor of California improved. The chief difficulty of the present is the circumscribed character of labor's opportunity. Give us twice the number of our present cities, or double the population of those already existing, and the possibilities of all life would be greatly expanded. The chief difficulty of the present is the irregular character of employment. The fruit industry of our State gives greater proportionate employment to labor than the cereal industry.

I have taken a single instance, but at the same time the most notable, of the irregularity of employments. The vineyard owned by Senator Stanford is the largest in the world. It covers 3,900 acres of bearing vines. It is operated under a single control, and is the largest operation of its kind known. The statistical facts relating to it would be the equivalent of statistical facts relating to 39 vineyards of roo acres each, and the facts are as follows: Exclusive of any labor, employed in planting, or grafting old vines, the operations of the vineyard require the labor of 135 men 
for six months ; that is the maximum requirement of the period of cultivation; then comes the vintage. This requires the steady employment of 500 men every part of two months, but for three weeks of that period, the demand will be for 700 men. For steady annual employment, but seventy men are required. Here we have a minimum of annual employment equal to seventy men, for the period of cultivation 135 men, and a maximum during the vintage of 700 men. The maximum is ten times the minimum in this case. There are about 200,000 acres of bearing vineyard in this State. Carrying the proportions derived from an exhibit of the great vineyard into the entire vineyard interests of the State, and the 200,000 acres of vineyard in this State would give us annual employment for 3,500 men. It will at once be seen that if grape-growing was the sole industry of the State, the 3,500 men who would find in it steady employment, would be the only available labor for the vintage, and they would be grossly inadequate. As has already been shown, the vintage requires ten times as mariy men as the industry affords annual employment. It would be impossible to have the labor of nine men available for a few months in the vintage season for one man who might find steady employment. The value of a diversified industry comes into view, and with the accession of populations, industries become more diversified. In this way, history has repeated itself in every State of this Union. The statistics of employments in every State show an increase of diversity exactly proportioned to the volume of population. In their early history, and when population was sparse, in the western states of Indiana, Illinois, etc., the great staples of wheat, corn and pork were the objects of cultivation. Some of these states have a history of over eighty years ; they have completed eight decades; and the testimony of eight census ascertainments declare unmistakably that as their populatious have increased, the diversity of employments has correspondingly augmented. With us the diversity of field culture enables us to achieve our present measure of success, but we are under serious disadvantage with respect of labor. This disadvantage, however, is rapidly passing away, but the existing condition plainly invites intelligent industry. For the past ten years the conditions of the labor market have been growing better. The influx of the Chinese has been permanently and effectively arrested. The increase of manufactures, which accompanies the growth of the State, offers with the lapse of each year more steady and more profitable employment to labor.

AREA, POPULATION AND IRRIGATION.

Up to within a comparatively recent period, the territorial area of California was placed at I8r,000 square miles, or II5,000,000 acres. A more recent, aud perhaps a more accurate demonstration of the fact, places the territorial area at 157,000 square miles, or $100,000,000$ acres. Instituting a comparison with some of the older States, and selecting the 
State of Ohio, because it is neither the largest nor the smallest, but approximately an average State, and California embraces four times, the area of Ohio, the ascertained area of the latter State being 24,640000 acres.

The question of the proportion of the arable land in the State of California to the entire acreage, has been much discussed. The pioneer population regarded but a very small portion as suitable for cultivation. Many large areas rejected as possessing no agricultural value whatever in the first decade of American occupation here are now among the most productive and valuable of any lands in the State. The methods of agriculture pursued here are of comparatively recent discovery and practice. Being the result of experiment under climatic conditions wholly different from those obtaining on the Atlantic seaboard, the agriculture of California may be said to be distinctive and peculiar. As now admitted to be applicable to the varying conditions of the different portions of the State, the area of arable land in the State may be presented as follows :

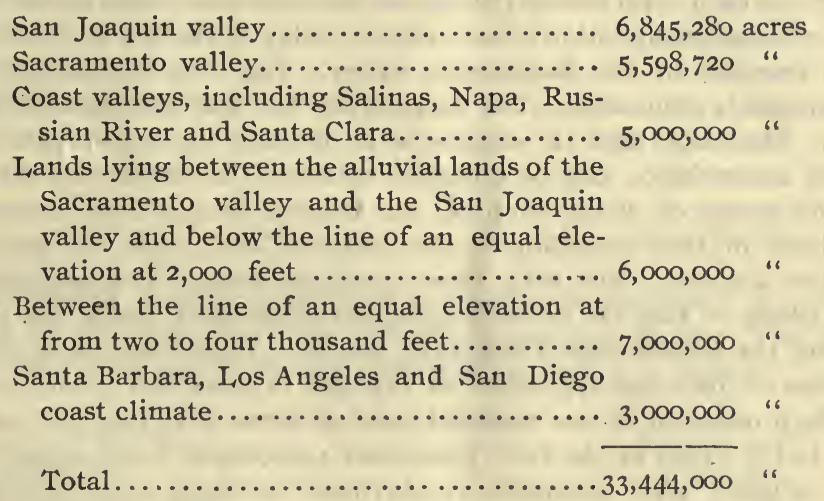

Thus the present ascertained area of arable lands aggregates $33,444,000$ acres. The irrigable area of the San Joaquin valley by definite ascertainment is $5,545,2$ So acres. In a large proportion of this area there is sufficient annual rainfall to mature annual crops of cereals, but the acreage above shown as irrigable is irrigable from the water shed of the western flank of the Sierra Nevada mountains. To this must be added about $1,500,000$ acres on the west side of the San Joaquin valley, excluded from the State Engineer's report as not receiving sufficient annual precipitation of moisure to mature crops of cereals, but irrigable from storage reservoirs in the Coast Range.

The acreage of the Sacramento valley is $5,598,720$ acres. This entire acreage receives sufficient rainfall to mature annual crops of cereals. The Sacramento and the San Joaquin valleys together comprise twelve per cent of the entire acreage of this State. 
Of the arid land south of the Tehachapi not included in the above calculation, there are at least $5,000,000$ acres reclaimable by irrigation.

The possible arable acreage of California may be therefore set down at $38,000,000$ acres.

Much of the timbered slopes of the Sierra Nevada Mountains and also of the Coast Range when cleared, are suitable for the production of red clover, timothy and many of the fruits of the temperate zone. Their timber resources, however, are the source of great wealth, the annual value of the lumber produced in the forests being estimated for several years at $\$ 7,000,000$ per annum.

There is no portion of California which would not be greatly benefited by the development of systems of irrigation. The valley of the Po, embraced within the provinces of Lombardy, Piedmont and Valentia, in Italy, comprises $5, \mathrm{I} 20,000$ acres, or 380,000 acres less than the arable acreage of the Sacramento valley. The two valleys of the Po and the Sacramento have many points in similarity. First, the area is about equal. Second, the single central drainage runs through the entire length of each, with lateral tributaries from the mountains on both sides. The annual precipitation of rain on the valley of the Po is about twice that received in the Sacramento valley. The river Po has thirty very considerable tributaries. The Sacramento has ten considerable tributaries. The arable area in acreage is in favor of the Sacramento valley. Close resemblance may be observed between the fertility of the soils, the clemency of winter climate, the tropical heat of the summer, the facilities of transportation to the seaboard, etc., and the contiguity to the seacoast. But with these, parallels cease. The population of the valley of the Po exceeds 9,000,000 inhabitants, while the population of the Sacramento is less than 200,000 . Over $8,000,000$ of the population of Italy are registered as engaged in unskilled occupations or in the production of raw materials, and of these, over one-half are credited to the valley of the Po. Thus, over $4,000,000$ of inhabitants find in the irrigated area profitable employment for their labor, where over a like area in Califoruia, depending wholly upon the annual precipitation of rain, 200,000 people begin to feel what is called the pressure of population.

Reduced to cultivation by systems of irrigation, and Sacramento and the San Joaquin valleys could be occupied by $20,000,000$ of people, without exceeding the density of the population of the valley of the Po.

Concerning the coast counties, the most considerable valleys are those of Salinas, Santa Clara, Napa and Sonoma; that is to say, Santa Clara, Napa and Sonoma present the greatest density of rural population in California. Tliey are under the highest state of cultivation in conformity with the most approved methods of agriculture and horticulture as justified by experience and developed by practice. They are devoted chiefly to the production of wines and fruits, and while wine making and fruit growing are not by any means confined to them, they furnish an excellent illustration of the superior return made to labor by the diligent and 
intelligent cultivation of that great diversity of product so favored by the climate of California. The fruit and the wine product of the year I888 aggregated in value $\$ 25,000,000$. Of this sum, at least sixty per cent, or $\$ 15,000,000$, is to be credited to the three valleys under consideration.

The acreage of California devoted to barley, corn, oats, rye and wheat aggregates $2,560,000$ acres. The value of the product for the year 1888 was $\$ 49,000,000$. The acreage devoted to fruit is about 240,000 acres equal to about nine per cent of the acreage devoted to cereals, and yet the product of the orchards and vineyards was valued at $\$ 25,000,000$, or fifty per cent of the value of the crop of cereals for that year.

The distinctively agricultural population, excluding those engaged in horticulture, in this State, is less than 100,000 inhabitants, including juvenile members of families and agricultural laborers. And yet carefully compiled statistics of the value of the product of field culture, excluding fruit, for the year I888, exhibit the following:

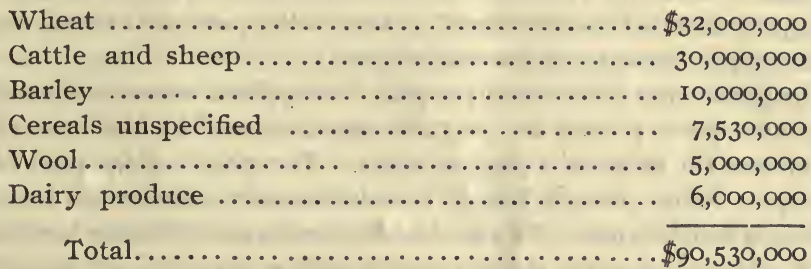

The operative mining population of California, including as abovespecified, minors and employed laborers, is less than 80,000 . The product of their labor compiled from authentic sources, is as follows :

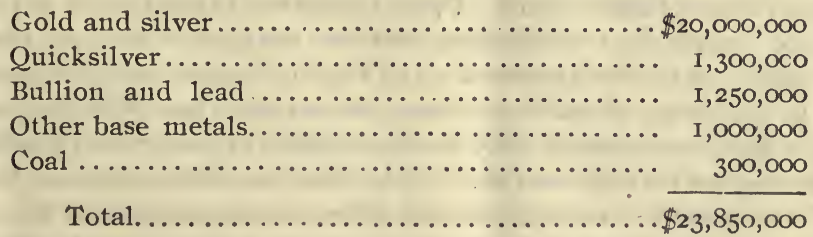

Thus while the populations engaged in the two classes of industry are approximately the same, the aggregate of the mining product scarcely reaches thirty per cent of the value of the field culture. But if we add to the $\$ 90,530,000$ given as the value of the agricultural products of the State for the year I888, $\$ 25,000,000$ the ascertained value of the fruit and wine product, we have $\$ I I 5,530,000$, as to the total annual product of field culture, thus reducing the annual output of the mining industry to less than twenty-five per cent of the value, notwithstanding approximately the same number of people are engaged in the two general classifications of industry. 
In the foregoing, the acreage of arable land is estimated at about $39,000,000$ acres. The great diversity of product favored by the climate will eventually give employment to a much larger number of people than could find employment upon a similar area in the temperate zones of the United States. The State of Ohio, which has already been used for the purpose of elucidation, which comparison always affords, devoted in the year $18883,577,000$ acres to the production of cereals, including all species of field culture, and the population of that State by the estimates of 1885 was $3,725,000$, or approximately three times the population of California. A cursory comparison with other States of the Union appears to confirm the claim quite fully that California has the largest area of land under cultivation in proportion to its population of any portion of the civilized world, and that the product of industry per capita is also greater than that which rewards the industry of any other people. Yet the most fertile and the most valuable portions of the arable land of California are wholly unused, owing to the aridity of the climate. This has reference in the main to San Joaquin valley. Of the $6,845,000$ acres of alluvial land in that valley, not to exceed 800,000 acres have been brought under cultivation.

The irrigable area of the San Joaquin Valley from water now available without storage is placed at $5,845,280$ acres, exceeding the area of the valley of the Po by over $1,725,000$ acres. The physical features of the San Joaquin Valley present simply a monotonous recurrence of level and exceedingly fertile lands. To say that this vast area of fertile land, lying under a climate favoring the greatest possible diversity of product, is in the infancy of its development, would not be so nearly an accurate presentation of fact as to say that the region is wholly undeveloped.

Generalizing these facts, we have a population of $1,200,000$ inhabitants, occupying a territorial area of 157,000 square miles, in which is embraced $33,444,000$ acres of arable land. Upon a less area, in the empire of Japan, $35,000,000$ people find subsistence, and are living, in a state of plenty, which admits of the development of all the higher attributes of civilization. In the valley of the Po, in area 380,000 acres less than the arable extent of the Sacramento Valley, seven millions of people find profitable employment for their industries. With these boundless resources before us, we may extend a welcome to our fellow countrymen from the more densely settled portions of our country, with every assurance that here a great empire of wealth and population awaits only the creative influence of intelligence and enterprise.

THE VALUE OF I,AND.

It has been contended with more or less plausibility that the high price at which the lands are held in California is arresting its growth and development. After an exhaustive inquiry into the subject, I am disposed to think that this charge must be plainly met, and that the real facts must be presented to the world. 
Since the year 1869 the extension of railroad lines into sparsely settled or wholly uninhabited territories of the United States has opened to settlement an area so vast as to distribute thinly the great tide of immigration which annually overflows from the more densely populated portions of this country and Europe. The railroad extension referred to opened vast areas of sparsely settled and uninhabited territory and brought these into competition with each other in the field of invitation to settlement. Since that period the State of Kansas received a million of inhabitants, Texas 1,600,000, Minnesota 70,000, Dakota 600,000, Nebraska 500,000, Wyoming 300,000, Washington 100,000, Montana 100,000, Arizona 50,000, Colorado 400,000, and California, according to the census report, about 500,000. Of all these, the growth of Kansas has been the most phenomenal. The reason for this is not far to seek. Kansas was more accessible than any of the Pacific Territories, and lands there were cheap. In estimating the obstacles to settlement of a distant region the cost of reaching that region must occupy a prominent place. It has cost more money in the past to remove a body of population aggregating roo,ooo men from the more densely populated and overflowing sections of our country to California than to remove $I, 000,000$ from the same sections to Kansas and Nebraska. The value of land superficially in California received a high development in advance of the density of population. In common observation, good agricultural land is deemed to have reached its highest point of value at from $\$ 30$ to $\$ 50$ an acre. A greater density of population, of which we have had no experience in California, will urge these prices up from $\$ 60$ to $\$ 75$ an acre, and if the lands are fertile as in Belgium, and the population equally dense with that country, they will reach the value of $\$ I, 000$ to $\$ I, 500$ an acre. Under these circumstances they become garden lands with immediate home market, but lands in California were sold for from $\$ 30$ to $\$ 50$ an acre when lands in Kansas and Nebraska could be obtained at the single minimum of $\$$ I.25 an acre, or within railroad limits at $\$ 2.50$ an acre. When, therefore, the immigrants had their choice between Kansas, Nebraska, Colorado, Minnesota and Dakota, where lands could be obtained at $\$ 1.25$ an acre at first hand from the Government, or at from $\$ 5$ to $\$$ io an acre at second hand, as against land in California, which was held at from $\$ 15$ to $\$ 30$ an acre, the immigrant chose the former location, under the somewhat justifiable but mistaken belief that lands in California had reached their full development: I beg to introduce the statement of fact that the average value of agricultural lands in the Sacramento valley have not yet reached $\$ 25$ an acre. The more fertile alluvial lands, suitable for growing fruits, and in the localities where the fruit is early, and where the environment is peculiarly favorable to fruit growing, lands are held at a valuation of from $\$ 50$ to $\$ 75$ an acre. In the pamphlet literature which is distributed at the East the statement is made that good fruit land can be obtained in California for from $\$ 75$ to $\$$ I 50 an acre.

I am painfully conscious, from personal observation, of the effect this produces on the mind of the Eastern agriculturist. Let us illustrate this : 
The intending immigrant is not content with second-class land. He, therefore, contemplates the purchase of the best quality, or the highest figure used in this illustration, $\$ 150$. Suppose he has at home 200 acres whicl he can sell at $\$ 50$ an acre, he will obtain $\$$ IO, coo for his farm. He realizes that at $\$ 150$ an acre he can purchase in return for this, after paying his expenses to California, say 60 acres. He, therefore, feels to be losing 140 acres by his change of residence, and there is a spirit of greed in the ownership of the earth's surface which makes this proposition instiuctively distasteful.

But the figures I have given here are not the maximum figures by any means. In recent pamphlet publications relating to Southern California, it is plainly stated that good orange land can be purchased for $\$ 250$ an acre. I read these statements, in the light of personal observation among the people of the East, and, therefore, have a better realization of their deterative force. The farmer in Iowa with 200 acres, saleable at from $\$ 40$ to $\$ 50$ an acre, realizes that the proceeds of the sale of his farm will purchase only one-fifth of its area in Southern California. He must, therefore, content himself with giving up 200 acres and becoming the proprietor of only 40 acres. This is analagous to the condition which existed during the period of the' great premium on gold. While California maintained a gold standard, the fortunes of Eastern people were convertible into greenbacks, but if they chose to emigrate to California, they must convert their greenbacks into gold. The farmer who could sell his farm for $\$ 20,000$ in greenbacks, after removal to California, must submit to a reduction of from $\$ 10,000$ to $\$ 12,000$ on the face value of his money, before he would have the only currency recognized by the commerce of this State. However clear a case might have been made for the equivalent value of the specie into which the currency had been converted, the sentimental considerations were against the change, and sentiment is not without influence even in matters of commerce. The reverse of this operated to send our population eastward. The man who could raise $\$ 10,000$ in gold coin in California, could convert it into $\$ 20,000$ of the currency in use in the Eastern States. Subsequent events proved that there was something more than sentiment in this, because the purchasing power of currency eventually arose to a par with gold. The gain became something more than apparent-it became actual. I declare herein unqualifiedly that the analogy of this, as relates to land, is the chief difficulty in immigration to the State of California. At the same time I declare that this reason is not justified by the real facts of the situation. The lands held at $\$ 150$ an acre in California are cheaper than any lands within the boundaries of any of the five great Western States at $\$ 50$. It is, however, not an easy task to justify this statement to the full comprehension of the intending immigrant, or to secure complete acceptance of its truth; but it is clearly within the knowledge of you, gentlemen of the Board of Agriculture, that lands in California which have a ready market value of $\$ 150$ an acre, are capable of producing a far better rate of interest on that investment than any lands which may be obtained in the corn, wheat and pork regions of the West at one-third that figure. 
In collecting data for this address, I have made extended inquiry as to the actual profit obtained from fruit growing in the fruit-growing sections of the State. The instances of a net average profit of $\$ 100$ a year continuing for a long period are not rare. Mr. A. T. Hatch, one of the most experienced fruit growers in the State, has given the assurance that the fruit lands of Califcruia are yielding a net annual profit of from $\$ 50$ to $\$ 100$ an acre. The fruit product of ninety-seven acres at Vacaville, hanging upon the trees, was sold during the present season for $\$ \mathrm{I} 8$, 000 in cash, the payment being made before any of the fruit was removed. About three years ago W. L. Buck of Vacaville, purchased from Thomas Wilson of that place 150 acres of land planted to orchard for $\$ 90,000$, being at the rate of $\$ 600$ per acre. The trees planted thereon were for the most part in bearing at the time. They are now in full bearing, and the fruit product of this year on the trees is estimated to be worth $\$ 30,000$, or $\$ 200$ per acre.

But let us here use the most conservative figures, furnished by $\mathrm{Mr}$. A. $T$. Hatch, and declare that $\$ 50$ an acre is the reasonable expectation of profit to the fruit grower. Lands upon which this profit may be realized, may be had for $\$ 100$ an acre. Here then an agriculture may be prosecuted which returns a net annual profit of one-half the original value of the land. It is, or should be, well known to you, as it is well known to the cultivators of the soil in the great agricultural States of the West, that an annual profit of from six to ten per cent would be regarded an extremely satisfactory result on the lands valued at from $\$ 40$ to $\$ 50$ an acre. But there are large areas of land in California which may be purchased for from $\$ 30$ to $\$ 40$ an acre, and which if devoted to those productions, permitted by the higher possibilities of climate, would make them worth from $\$ 300$ to $\$ 500$ an acre within a short period of time. When the Eastern mind has accepted the conclusion, for which the people of California have contended for many years, the accession of population will be as rapid as has been observed in the Western States. When it is understood that lands, which may be purchased for $\$ 50$ an acre, are easily susceptible of becoming worth three or four times that sum and that lands valued at $\$ 100$ per acre may readily become worth $\$ 500$ an acre, the intending immigrant will be no longer deterred from casting his lot with us, because the number of his acres must be diminished. The true standard of estimation of the value of land is not by any unit of area, but by the unit of fertility, and by the standard of units relating to the possibility of a higher use for the land. Acres may express the extent of surface, but when value is under consideration, climatic possibilities and fertility are the controlling factors. The true method of determining values is by productiveness rather than surface extent.

A recapitulation of the foregoing considerations presents our State as in the very infancy of its development. The industries upon which we are founding a commonwealth have had less than twenty years of history.

We have but recently, even but now, acquired that intelligent percep- . tion of our environment which will enable us to avail of the higher possibilities of our soil and climate. 
We are no longer remote in a commercial aspect from the great centers of commercial activity.

Economic methods of communication have conferred upon us the equivalent of physical contiguity with the rest of the world.

More intelligent methods of agriculture, improved conditions of the labor market, combined with the constant decrease in the cost of transportation, afford assurances of the permanency of all our industries.

Our State has a territorial area of 157,000 square miles, comprising an arable area of $35,000,000$ of acres, capable of supporting ten times the population now in occupancy. We have a climate which admits of the economies of production as relates to every industry, and confers upon us the broadest diversity of production and the largest future possibilities. We have large areas of land under the conditions of primitive development as to values.

These facts constitute in themselves a strong invitation to the home seekers among our countrymen.

The love of Californians for their State, which is proverbial throughout the world, has ample justification. Where else on the earth is there more inspiring cause for love for one's country? In what other country is there broader freedom of thought and action? In what other country are the alluring prophesies, which attend the hopes of young life, more certain of fulfillment, or in what other country do greater blessings of peace and plenty minister to the comforts of age?. In what other country is honest industry more respected, or does labor earn a higher meed of profit and honor? Under our summer suns the fruits of the tropics ripen without the torrid rigors of the equator. Here the russet brown of our summer hills and the golden stubble of the after harvest are the only winter we know. Here the verdure of spring ushers in the autumn, and the autumn brings no forewarning of the bleak discomforts of winter. Here winter is the season when the warm brown earth is turned by the plow for the seed time, and spring, with its flowers and ripening grain, is opulent with the fruition of hopeful industry. Nor are these all the attributes which challenge our love. Here nature has wrought its best enchantment in the sublimity of mountain heights, the bold grandeur of cliffs, the pensive peacefulness of lovely valleys and the expansive splendor of fertile plains.

Looking backward, we see a history founded in the romance of adventure. In the present, we are laying the foundations of a noble commonwealth by the establishment of permanent industries. If patriotic devotion attends upon our love, and high endeavor is the inspiration of our pride, they will ripen for our beloved State its growing harvest of hope. 

RETURN TO the circulation desk of any University of California Library or to the

NORTHERN REGIONAL LIBRARY FACILITY Bldg. 400, Richmond Field Station University of California Richmond, CA 94804-4698

ALL BOOKS MAY BE RECALLED AFTER 7 DAYS 2-month loans may be renewed by calling (415) 642-6233

1 -year loans may be recharged by bringing books to NRLF

Renewals and recharges may be made 4 days prior to due date

\section{DUE AS STAMPED BELOW NOV 191988}

\section{Returned by}

NOV 281987

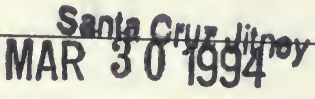

\section{'JAN 02.2003}




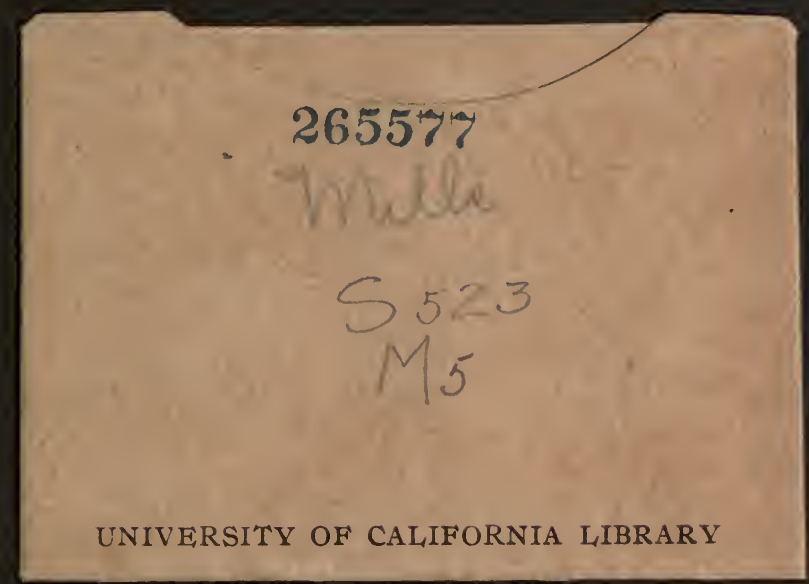




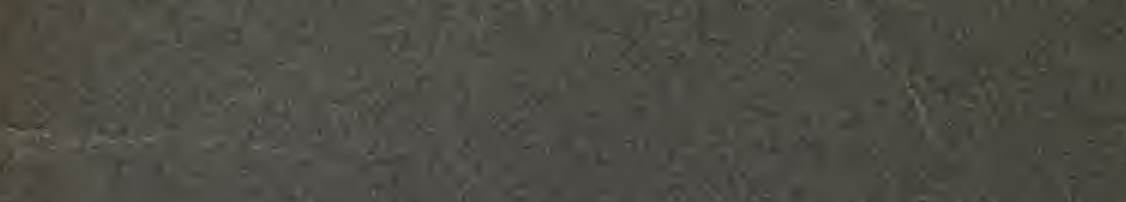

$3-3 y^{2}=x^{2}$

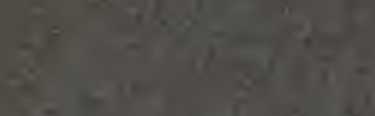

3

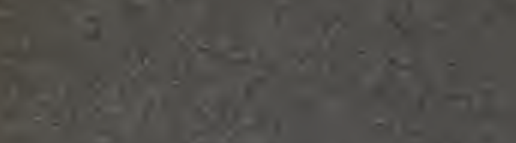

is $\sin (x)$

1) 18

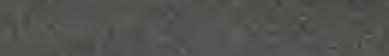

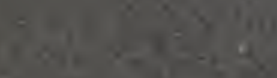

$\operatorname{tin} x$

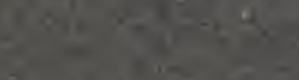

$x^{2}-4+4+2+1=$

$-y^{2}+y^{+3}+2+1=$

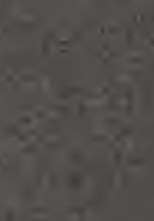

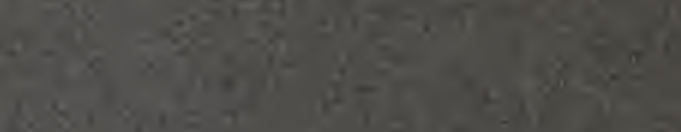

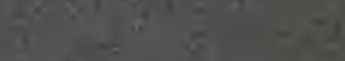

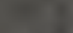

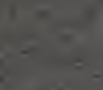

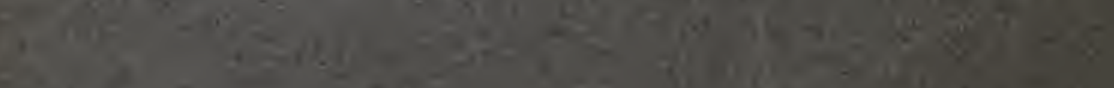

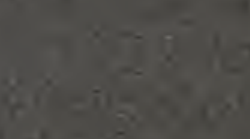

$x+\frac{1}{x+1}=$

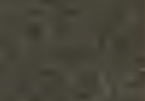

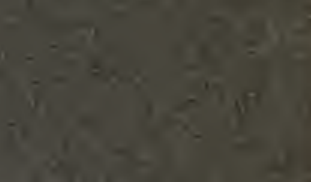

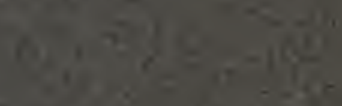

(1)

28

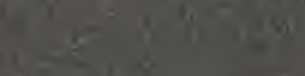

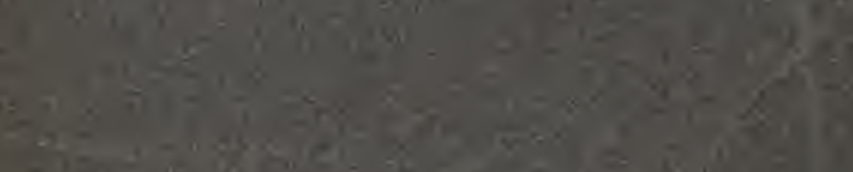

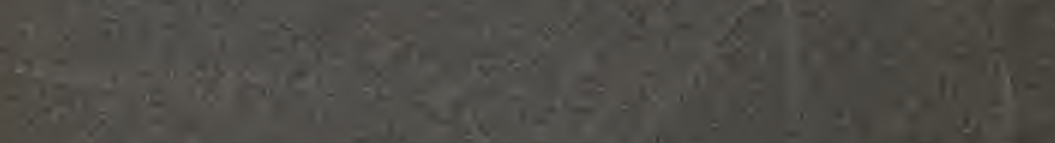

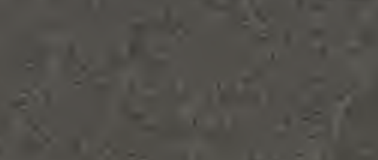

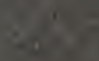

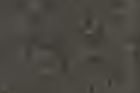

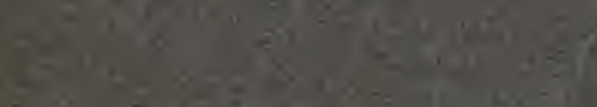

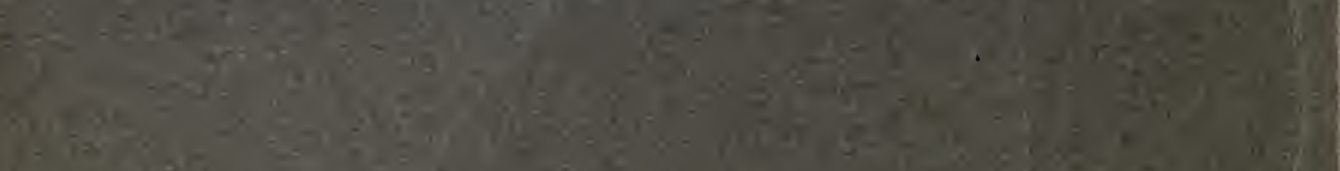

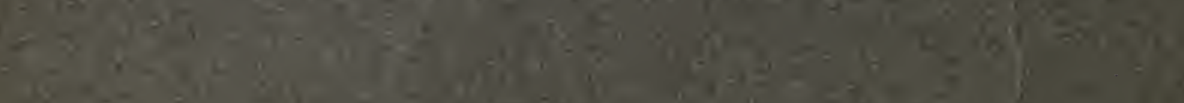

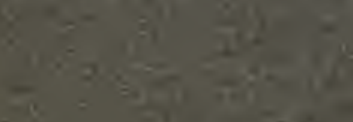

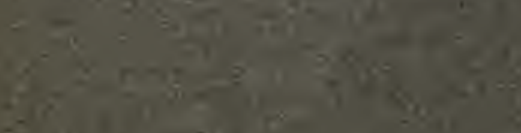

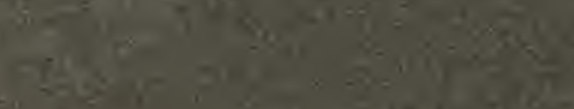
is

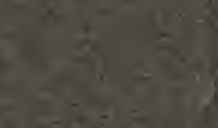

